\title{
Development of "Kanako", a wide use 1-D and 2-D debris flow simulator equipped with GUI
}

\author{
K. Nakatani, T. Wada, Y. Satofuka \& T. Mizuyama \\ Laboratory of Erosion Control, Graduate School of Agriculture, \\ Kyoto University, Japan
}

\begin{abstract}
Debris flows often cause substantial losses to human life and the economy. Damage can be effectively reduced using numerical simulation models, which can describe the debris flow process and determine possible effects of sabo dams, or erosion and sediment control dams. However, non-experts find it very difficult to run simulations independently, because the systems do not currently have an efficient user interface. We developed a system that produces one- and two-dimensional debris flow simulations and is equipped with a graphical user interface (GUI). The system is based on an integration model and employs onedimensional simulations for gully areas and two-dimensional simulations for alluvial fan areas, and then considers their mutual influence in boundary areas between gullies and alluvial fans. The system was developed with "MS Visual Basic.NET." Data can be input using a mouse and be checked on the monitor, users can see real-time visualized images of the debris flow during the simulation. The interface enables non-expert users to run the debris-flow simulation independently, enabling better solutions for sabo engineering.
\end{abstract}

Keywords: debris flow, graphical user interface (GUI), numerical simulation, one- and two-dimensional integration model.

\section{Introduction}

Debris flows can cause severe damage in gullies and alluvial fans and Sabo works is to reduce and prevent sediment disaster such as debris flows. Sabo dams, or erosion and sediment control dams, effectively prevent and reduce disasters caused by debris flow, and many sabo dams have been constructed in Japan. These dams can reduce the energy of a debris flow, thereby controlling 
the surface erosion that usually occurs in upstream areas. For most efficient results, sabo dam design (e.g. type, location, size) must be customized to each specific area. Researchers have recently proposed a variety of numerical simulation models (Takahama et al. [1], Egashira and Itoh [2]) and some have been put to practical use when designing sabo dams.

However, many users have not been enthusiastic about these systems. The processes and display are difficult to understand and require specific training to operate, and users find it difficult to prepare the various datasets and parameters. Thus, users who are not experts on debris flow simulation (e.g. sabo engineers) are unable to run simulations independently and are forced to rely on specialists.

As models become increasingly complex, the knowledge gap between specialists and engineers is widening, making simulations a complicated and impractical tool for sabo engineering. If researchers continue to focus on debris flow simulations by simply testing the accuracy of existing models or developing new models, the systems will continue to be impractical.

To address this problem, we developed a system equipped with a userfriendly graphical user interface (GUI), which will enable non-experts to run numerical debris flow simulations independently.

\section{Kanako Ver.2.00 system}

\subsection{Platform}

We developed our system using MS Visual Basic.NET (VB) because this platform was designed to run on Windows. It also provides an interactive GUI and is easy for beginners to learn. There is a common misunderstanding that VB performance is easy to use but has low-function, but VB is actually both easy to use and yields high performance. Because the platform is so widely used and easy to learn, users can easily modify and extend the system.

\subsection{Graphical user interface (GUI)}

A user interface is the means by which users interact with a particular machine, device, computer program, or the system. A GUI enables users to interact with media formats (e.g. PC) that employ graphical icons to represent information and available actions to a user. Users normally perform actions by directly manipulating the graphical elements.

To ensure the system easy for beginners to use, datasets used in simulations can be input using a mouse and checked on the monitor. Users can view realtime images of debris flows, hydrographs, and the effects of sabo dams, during the simulation. The GUI enables users without specialized training to identify better solutions effectively and to run debris-flow simulations independently.

\subsection{Developed system}

Our GUI-equipped debris flow simulator is called "Kanako." Kanako Ver.1.10 (Nakatani et al. [3]) can simulate one-dimensional (1-D) debris flow and the effects of sabo dams. In this study, we developed Kanako Ver.2.00, which can 
simulate 1-D debris flow in gullies and two-dimensional (2-D) debris flow in alluvial fans.

\section{Numerical simulation model}

The system applies an integration model (Wada et al. [4]). For gullies, it uses a 1-D numerical simulation model to reproduce variations in a mountain riverbed caused by debris flow and to simulate the effects of closed, slit, and grid types of sabo dams (Satofuka and Izuyama [5]). For alluvial fans, it uses a 2-D numerical simulation model to reproduce changes in flow depth and sedimentation to simulate the passing area of debris flow.

Previous models have simulated the boundary areas between gullies and alluvial fans using the 1-D downstream end result as the 2-D upstream boundary condition. In contrast, our integration model simulates both 1-D results for gullies and 2-D results for alluvial fans at each time step, incorporating mutual influences of both models. This enables the system to reproduce more accurate results, especially when marked sedimentation occurs in a boundary area.

\subsection{Governing equations for debris flow}

The basic 2-D debris flow equations are shown below. The same equations are applied in 1-D debris flow simulations without $y$-axis direction terms. Momentum equations, continuation equations, riverbed deformation equations, erosion/deposition equations, and riverbed shearing stress are based on Takahashi and Kuang [6], and the staggered scheme and arrangement of variables are based on Takahashi and Nakagawa [7].

The continuation equation for the total volume of debris flow is:

$$
\frac{\partial h}{\partial t}+\frac{\partial u h}{\partial x}+\frac{\partial v h}{\partial y}=i
$$

The continuation equation for determining particle $k$ th grade is:

$$
\frac{\partial C_{k} h}{\partial t}+\frac{\partial C_{k} h u}{\partial x}+\frac{\partial C_{k} h v}{\partial y}=i_{k} C_{*}
$$

Here, we can consider two grain-size classes for sediment material. The phenomenon of $x$-axis direction (flow-direction) flow uses a momentum equation, as follows:

$$
\frac{\partial u}{\partial t}+u \frac{\partial u}{\partial x}+v \frac{\partial u}{\partial y}=g \sin \theta_{w x}-\frac{\tau_{x}}{\rho h}
$$

The phenomenon of $y$-axis direction (cross-direction) flow uses a momentum equation, as follows:

$$
\frac{\partial v}{\partial t}+u \frac{\partial v}{\partial x}+v \frac{\partial v}{\partial y}=g \sin \theta_{w y}-\frac{\tau_{y}}{\rho h}
$$


The equation for determining change in bed surface elevation is as follows:

$$
\frac{\partial z}{\partial t}+i=0
$$

For eqn (1) through (5), $h$ is flow depth, $u$ is $x$-axis direction flow velocity, $v$ is $y$-axis direction flow velocity, $C_{k}$ is $k$ th sediment concentration by volume in debris flow, $z$ is bed elevation, $t$ is time, $i$ is erosion/deposition velocity, $i_{k}$ is $k$ th sediment erosion/deposition velocity, $g$ is gravity acceleration, $\rho$ is interstitial fluid density, $\theta_{w x}$ and $\theta_{w y}$ are the flow surface gradients in the $x$-axis and $y$-axis directions, $C_{*}$ is sediment concentration by volume in movable bed layer, and $\tau_{x}$ and $\tau_{y}$ are the riverbed shearing stresses in the $x$-axis and $y$-axis directions.

\subsection{Conditions for sabo dam design and simulation variables}

The numerical simulation model applies a staggered scheme using a finite difference method. Scalar and vector quantities are staggered by $\Delta x / 2$ (or $\Delta y / 2$ ) in the flow direction (or cross direction), as shown in Fig. 1. Sabo dams are set at the calculation point of flow velocity, as shown in Fig. 2. The effective flow depth, $h^{\prime}$, at the dam point, which is used to calculate the outflow flux, is expressed using the variables shown in Fig. 2, as follows:

$$
h^{\prime}=\left\{\begin{array}{cc}
h_{i}+z_{i}-z_{d} & \left(h_{i}+z_{i}-z_{d} \geq 0\right) \\
0 & \left(h_{i}+z_{i}-z_{d}<0\right) \\
h_{i} & \left(z_{i}>z_{d}\right)
\end{array}\right.
$$

where $z_{d}$ is the dam crest elevation, which is the sum of bed elevation and dam height. Here, $h_{i}$ is flow depth in the scalar evaluation point next to the dam position in the upstream direction and $z_{i}$ is the riverbed height at the same point as $h_{i}$ (fig. 2). In addition, at vector evaluation points where the sabo dam is not set, flow discharge is calculated using upstream side flow depth and velocity.

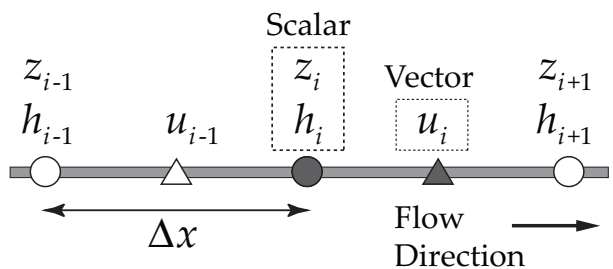

Figure 1: $\quad$ Arrangement of variables in a 1-D area. 


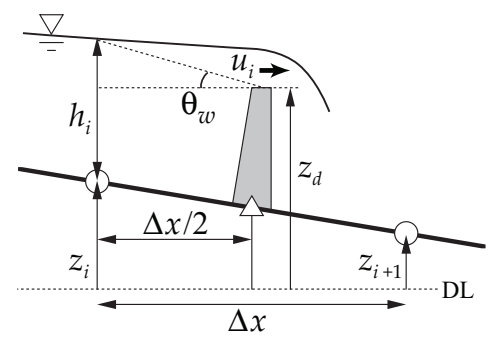

Figure 2: Arrangement of variables at a sabo dam.

\subsubsection{Simulation of a closed type sabo dam}

To examine upstream deposition velocity in a closed sabo dam, we can use a previously developed method (Takahashi et al. [8]) to calculate variations in a riverbed. This method uses a relationship between dam height and riverbed height at the dam's upper site to determine whether materials will pass over a sabo dam. When a dam's upstream side contains a pocket, materials and water can be separated easily. When the riverbed height is lower than dam height $\left(z_{i}<z_{d}\right)$, materials supplied from upstream are immediately deposited at that point.

\subsubsection{Simulation of a slit type sabo dam}

Kanako can simulate the effect of a slit sabo dam. When a slit dam is set, the system simulates the narrowing river width between upstream and downstream scalar evaluation points, from the vector evaluation point where the sabo dam is set. However, the model does not currently incorporate energy loss from the sharp narrowing of river width.

\subsubsection{Simulation of a grid type sabo dam}

When debris flows occurs in a mountainous river where a grid sabo dam is set, the opening of the grid dam is blocked by large rocks in the front part of the debris flow, which can cause the dam to trap the subsequent muddy flow as a closed type dam. In the model developed by Satofuka and Mizuyama [9], a grid dam is treated as a closed dam with a temporally variable height through the blockage. In the model, sediment material is composed of two grain-size classes; only the larger class of sediment causes stoppage of the grid dam opening and increases the dam height. The model estimates temporal changes in dam height using probabilities of the blockage being influenced by sediment concentration, flow depth, sediment diameter, and distance of grid dam columns.

\subsection{Integration model}

\subsubsection{Outline of the integration model}

Fig. 3 presents the integration model outline. It enables continual simulation of both 1-D models in gullies and 2-D models in alluvial fans at each time step. 


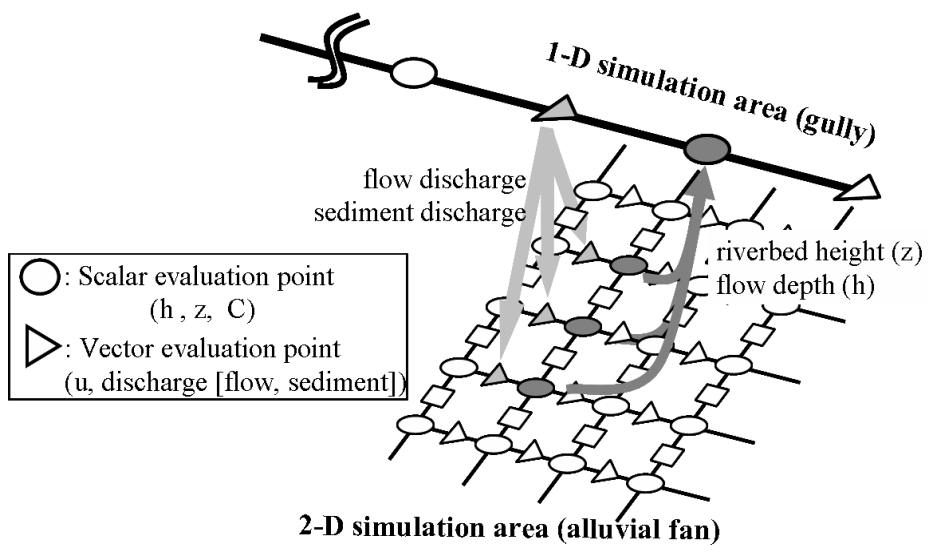

Figure 3: $\quad$ Outline of the integration model.

Using the 1-D downstream end-flow discharge and sediment discharge as the 2-D upstream inflow condition and using 2-D simulated riverbed height and flow depth as the 1-D downstream end condition, the integration model incorporates mutual influences of the 1-D and 2-D simulations. Moreover, this integration model can handle situations in which intervals of 2-D cross direction calculation points and 1-D river width differ or 1-D simulation flow direction and 2-D simulation flow ( $x$-axis) direction differ slightly.

\subsubsection{Integration of 1-D and 2-D simulation areas}

The 1-D downstream end calculation point number is set as ie, and the inflow point in the 2-D upstream end area's grid point coordinates are set as $(1, j c)$. Fig. 4 shows the integration of 1-D and 2-D areas, corresponding to the 1-D No. (ie1) vector evaluation point with the $2-\mathrm{D}(1, j c)$ vector evaluation point. In Fig. 4, $\Delta x_{1}$ shows the calculation point interval in 1-D, $\Delta x_{2}$ shows the $x$-axis direction

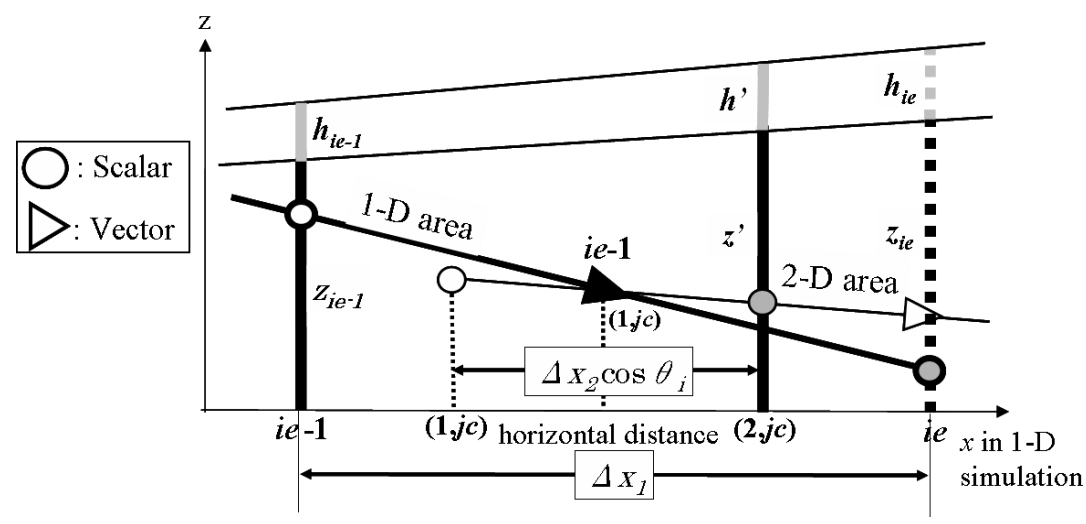

Figure 4: $\quad$ Profile of the integration area. 
grid interval in 2-D, $h_{i}$ and $z_{i}$ reproduce the flow depth and riverbed elevation of the 1-D area No. $i$ point, $h$ ' and $z$ ' reproduce the average flow depth and riverbed elevation of the 2-D area upstream end, and $\theta_{i}$ shows the angle between the 1-D $x$-axis and the 2-D $x$-axis. To integrate different dimensional simulation areas, we have to consider $\theta_{i}$.

As shown in Fig. 5, the 2-D grid interval in the $x$-axis direction is transformed to $\Delta x_{2} \cos \theta_{i}$ in the 1-D area, and the 1-D No. (ie-1) vector evaluation point river width is shown as $B_{i e-1} / \cos \theta_{i}$ in the 2-D area. In Fig. 5, $B_{i e-1}$ shows the river width at the 1-D No. (ie-1) vector evaluation point, and $\Delta y_{2}$ shows the 2-D grid interval in the $y$-axis direction.

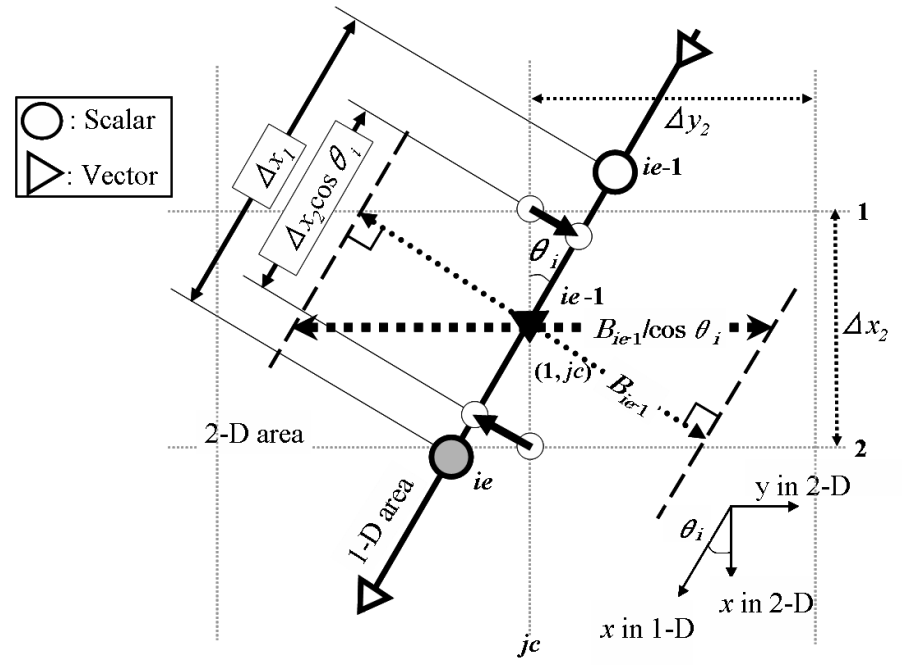

Figure 5: Plan of the integration area.

\section{Outline of Kanako Ver.2.00}

\subsection{Setting input data}

In the Kanako start screen (fig. 6), the graphic displayed in the upper part is the 1 -D riverbed profile, and the river width is in the middle, presented in meters.

The riverbed profile includes three parameters; the surface of the moveable bed, the surface of the fixed bed, and the river width. Each can be modified by dragging the point. Yellow points on the riverbed profile indicate hydrograph observation points, and black, gray, and blue checked rectangles indicate closed, slit, and grid type sabo dams. When a point is dragged, a guide appears to reveal the current position. Sabo dam parameters can be set in the sabo dam detail screen. User can set these by double-clicking on the sabo dam, causing a pop-up 
window of detailed dam settings to appear. Variable settings include height, type (closed, slit, or grid), and slit width can be set using text boxes or radio buttons. Other details for a grid type of sabo dam, such as column diameter and distance between columns, can be set in another screen. Dam position can be adjusted by dragging the rectangle right or left along the river profile. Supplied hydrograph from the upstream end and the number of calculation points can be set in other pop-up windows.

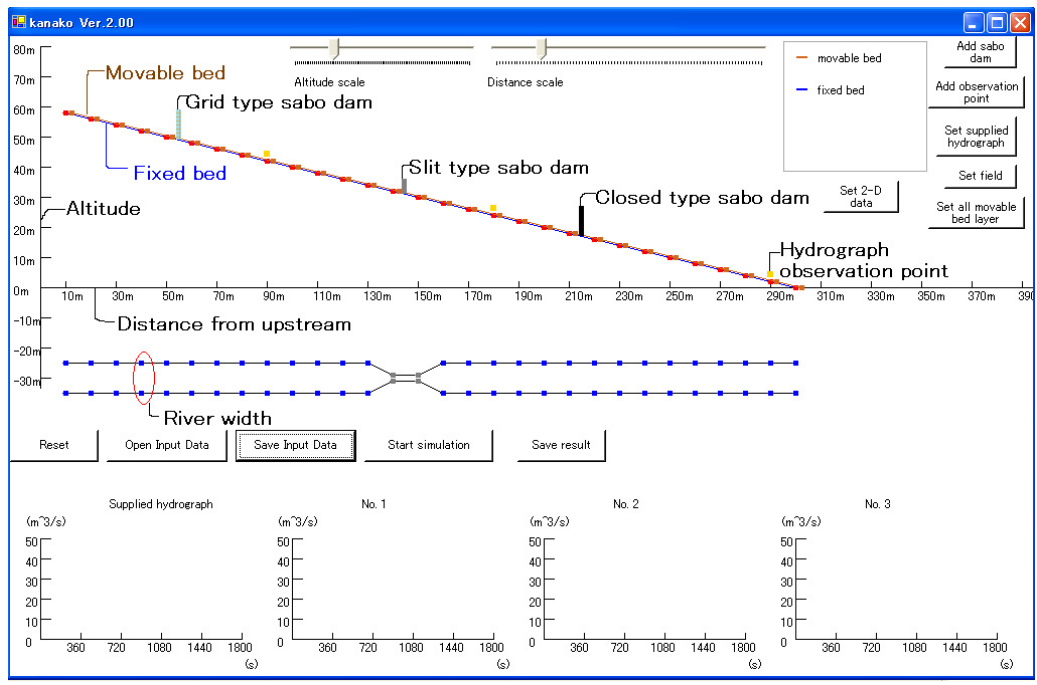

Figure 6: Kanako Ver.2.00 start screen.

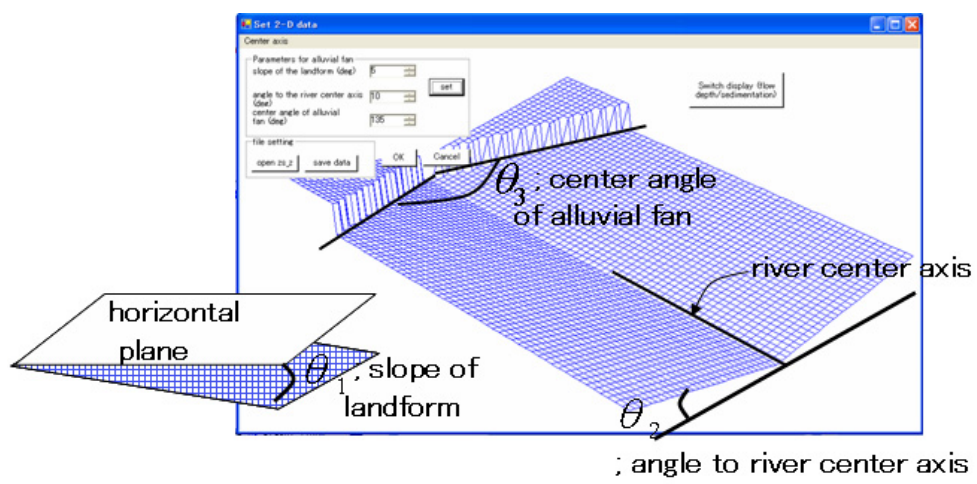

Figure 7: $\quad$ 2-D landform setting.

To set 2-D landform conditions, open 'set 2-D landform' window (fig. 7) and set parameters in group box; slope of the landform, angle to the river center axis, and center angle of the alluvial fan, shown as $\theta_{1}, \theta_{2}$, and $\theta_{3}$ in fig. 7. 


\subsection{Running a simulation}

As the simulation starts by clicking 'Start' button, debris flow is initiated and moves down from the upper stream. The 1-D simulation screen animates realtime image of flow depth, moving bed surface, initial bed surface, and fixed bed in the upper screen (fig. 8). Four graphs displayed at the bottom represent hydrograph and sediment graph, supplied from the upstream end and at each observation point. Here, the vertical axis represents debris flow discharge $\left(\mathrm{m}^{3} / \mathrm{s}\right)$ and the horizontal axis represents time (s). After debris flow reaches the alluvial fan, the 2-D simulation screen animates (fig. 9) flow depth and sedimentation to represent the passing area of debris flow.

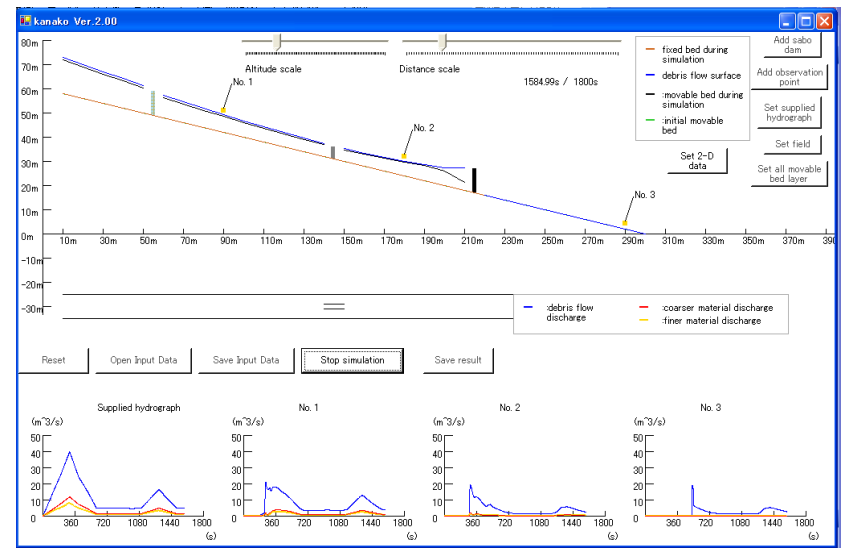

Figure 8: $\quad$ 1-D simulation screen.

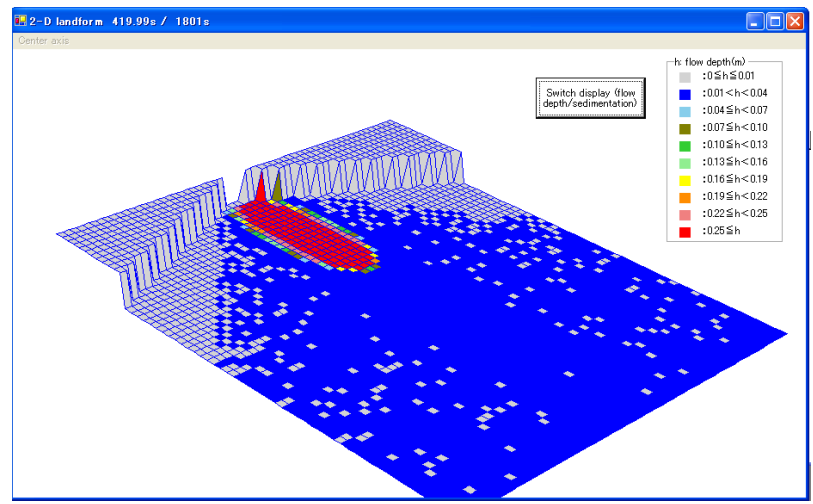

Figure 9: $\quad$ 2-D simulation screen showing flow depth.

The simulator calculates for a period of $1800 \mathrm{~s}$ and stops. User can preserve simulation results as a CSV data file following normal procedures for saving data. 


\section{Conclusions}

Kanako 2.00 is easier to use and provides more information to users than previously developed simulators. Users can easily input calculation conditions based on their needs, by using a mouse to click on the menu functions, and can check data using the displayed graphics. Simulation results can be understood intuitively. Therefore, users can conduct numerical simulations to calculate debris flow processes even without advanced training. In future research, we plan to improve the 2-D model with the use of GIS, so that Kanako can simulate debris flow from a mountainous river to alluvial fans from occurrence to stop.

\section{References}

[1] Takahama, J., Fujita, Y., Kondo, Y., Hachiya, K., Two-layer model for analysis of deposition and erosion processes of debris flows, Annual Journal of Hydraulic Engineering, JSCE, 46, pp. 677-682, 2002 (in Japanese with English summary).

[2] Egashira, S., Itoh, T., Numerical simulation of debris flow, Journal of Japan Society of Computational Fluid Dynamics, 12(2), Online (in Japanese) www.nagare.or.jp/jscfd/j-jscfd/122/p122-2.pdf.

[3] Nakatani, K., Satofuka, Y., Mizuyama, T., Development of 'KANAKO', a wide use debris flow simulator equipped with GUI, Proc. of 32nd Congress of IAHR, Venice, Italy, CD-ROM, 10p, A2.c-182, 2007.

[4] Wada, T., Satofuka, Y., Mizuyama T., Integration of 1- and 2-dimensional models for debris flow simulation, Journal of the Japan Society of Erosion Control Engineering, under review (in Japanese with English summary).

[5] Satofuka, Y., Mizuyama T., Numerical simulation of a debris flow in a mountainous river with a sabo dam, Journal of the Japan Society of Erosion Control Engineering, 58(1), pp. 14-19, 2005 (in Japanese with English summary).

[6] Takahashi, T., Kuang, S., Formation of debris flow on varied slope bed, Disaster Prevention Research Institute Annuals, 29(B-2), pp. 345-349, 1986.

[7] Takahashi, T., Nakagawa, H., Prediction of stony debris flow induced by severe rainfall, Journal of the Japan Society of Erosion Control Engineering, 44(3), pp. 12-19, 1991 (in Japanese with English summary).

[8] Takahashi, T., Nakagawa, H., Satofuka, Y., Kawaike, K., Flood and sediment disasters triggered by 1999 rainfall in Venezuela: A river restoration plan for an alluvial fan, Journal of Natural Disaster Science, 23, pp. 65-82, 2001.

[9] Satofuka, Y., Mizuyama, T., Numerical simulation of debris flow control by a grid dam, Proc. of the 6th Japan-Taiwan Joint Seminar on Natural Hazard Mitigation, CD-ROM, 2006. 